\title{
Affective commitment foci as parallel mediators of the relationship between workplace romance and employee job performance: a cross-cultural comparison of the People's Republic of China and Pakistan
}

This article was published in the following Dove Press journal:

Psychology Research and Behavior Management

Muhammad Aamir Shafique

Khan'

Du Jianguo'

Ahmed Abdul Hameed ${ }^{2}$

Tehseen UL Mushtaq ${ }^{2}$

Muhammad Usman ${ }^{2}$

'School of Management, Jiangsu

University, Zhenjiang, People's

Republic of China; ${ }^{2}$ Department of

Management Sciences, COMSATS

University Islamabad, Lahore,

Pakistan
Correspondence: Muhammad Usman Department of Management Sciences, COMSATS University Islamabad, Lahore Campus, I.5 KM Defence Road, Off Raiwind Road, Lahore 54000, Pakistan

$\mathrm{Tel}+9242$ III 001007

Fax+924299203100

Email hmusman10@yahoo.com
Purpose: The purpose of the present study is twofold. First, we examined the relationship between workplace romance and employee job performance and tested the role of affective commitment foci - namely, affective coworker commitment, affective supervisor commitment, and affective organizational commitment - as parallel mediators in the relationship between workplace romance and employee job performance. Second, we tested the moderating role of culture on the interrelationships between workplace romance, affective commitment foci, and employee job performance. Methods: A two-wave (3-month interval) survey data were collected from 312 paramedics 162 and 150 from Pakistani and Chinese public-sector hospitals, respectively. The first and second waves of data collection took place in January and May 2017, respectively. Structural equation modeling (SEM), bootstrapping technique, and multigroup analysis were used to test the interrelationships between workplace romance, affective commitment foci, and employee job performance and to examine the cross-cultural differences in these interrelations.

Results: Results obtained using SEM show that workplace romance positively influences employee performance. Importantly, the study revealed that the three foci of affective commitment - namely, coworker affective commitment, supervisor affective commitment, and organizational affective commitment - as parallel mediators fully mediate the relationship between workplace romance and employee performance. Moreover, national culture moderates the indirect relationship between workplace romance and employee job performance, where workplace romance is stronger for the Chinese data sample.

Conclusion: It is concluded that workplace romance is positively related to employee job performance and that affective commitment foci fully mediate the positive relationship between workplace romance and employee job performance. Moreover, culture moderates the indirect relationship between workplace romance and employee job performance. The study contributes to theory and practice by studying an essential but largely ignored aspect of the workplace and portraying it as a constructive influence on employee job performance and their affective commitment to coworkers, supervisor, and organization.

Keywords: workplace romance, job performance, affective commitment, paramedical staff, health sector, cross-cultural comparison, People's Republic of China, Pakistan

\section{Introduction}

Workplace romance is defined as a mutually consensual and committed relationship that can entail dating, touching, hugging, kissing, and sexual intercourse. ${ }^{1-4}$ Workplace 
romance can be hierarchical (between an employee and his/ her supervisor/manager or subordinate), lateral (between peers), heterosexual (between opposite sexes), and homosexual (between same-sex individuals). ${ }^{1-3}$ Research data are growing with regard to workplace romance and its outcomes discourse. The increased interest is mainly due to the acknowledgment that it can have pivotal implications - constructive and destructive - for employee job performance, job satisfaction, wellbeing, and organizational commitment. ${ }^{1,5-8}$

Literature proposes that workplace romance can have constructive effects on employee job performance, as participants of workplace romance work hard to improve their impression and performance to compensate for any negative perceptions related to their involvement in romantic relations. ${ }^{6,9-11}$ Workplace romance can be a source of happiness for the participants of workplace romance. ${ }^{6}$ The happy/ productive worker hypothesis suggests that happy workers can exhibit improved job performance. ${ }^{12}$ Moreover, Khan et al empirically showed that employees involved in workplace romance exhibit improved performance. ${ }^{1}$ As partners in a workplace romance feel psychologically safe, they are more open to new ideas and experimentation that can improve their job performance. ${ }^{7}$ Moreover, as participants of workplace romance have satisfied their companionship needs, they have more energy available to perform their jobs that is likely to improve their productivity and performance. ${ }^{9}$ However, workplace romance can have destructive effects on the performance and productivity of employees and organizations, as participants of workplace romance may devote their time at work to romance-related activities and ignore their job activities. ${ }^{8,13}$ Similarly, workplace romance can have destructive effects on participants in the romance that can manifest in the form of sexual exploitation, harassment, litigations, stress, and negative publicity. ${ }^{8,13}$ Destructive effects such as sexual exploitation, harassment, and litigation are often linked with hierarchical and dissolved workplace romances. ${ }^{2,10}$ However, in accordance with the happy/productive worker hypothesis ${ }^{11}$ and impression management theory, ${ }^{6}$ we expect that workplace romance is positively related to employee job performance.

Moreover, literature is indicative of the influence of workplace romance on employee affective commitment. ${ }^{6,10,11}$ We understand affective commitment as employee emotional involvement with their organization, coworkers, and supervisors that encourages them to commit time and energy to their work and go beyond performance norms. ${ }^{14,15}$ This conceptualization of affective commitment suggests that affective commitment is a multidimensional construct that can have different foci (can be directed toward different targets) such as organization, supervisor, and colleagues. ${ }^{14,15}$ Additionally, a plethora of studies posits a positive relationship between affective commitment and employee performance. ${ }^{15-17}$ This suggests affective commitment can mediate the relationship between workplace romance and employee job performance.

In addition, the literature suggests that the nature of effects of romantic relationships can vary across cultures, as culture is one of the fundamental factors that shape emotions, thoughts, feelings, behaviors, and romantic relationships. ${ }^{18-20}$ Thus, we propose that the national culture can moderate the behavioral and performance outcomes of a workplace romance. However, empirical studies comparing crosscultural differences in the relationship between workplace romance and employee job performance are nonexistent.

Thus, the aim of this study is to, first, examine the relationship between workplace romance and employee job performance and test the mediating role of affective commitment in the relationship between workplace romance and employee job performance. Then, we aim to examine the moderating role of national culture on the relationship between workplace romance and employee work-related behaviors and performance outcomes. Based on a two-wave survey of 312 paramedical staff from 13 public sector hospitals operating in two countries - Pakistan and People's Republic of China - we used structural equation modeling (SEM), bootstrapping and multigroup analysis to test these relationships.

This study is important in terms of theoretical and practical implications. Studying workplace romance is imperative because workplace romance is argued to be an important part of the social fabric of the workplace. ${ }^{1,6,7}$ Moreover, empirical literature on the relationship between workplace romance and employee job performance is scarce. Therefore, by providing empirical evidence of the relationship between workplace romance and employee job performance and showing the significant mediating role of affective commitment foci in this relationship, this study makes imperative contributions to the literature on workplace romance. A key contribution of our study is the cross-cultural comparison of the interrelationship between workplace romance, affective commitment foci and employee job performance relationship. Studying these relationships carries important implications for health-care service provision, given the vitality of the roles of paramedics in the provision of these services.

This paper is organized into five sections. In Section 2, hypotheses are developed. Section 3 presents research methods. The results are presented in Section 4. In Section 5, results are discussed, and the conclusions are presented. 


\section{Hypothesis development}

Workplace romance and employee job performance

Historically, the emphasis of the literature has been on sexual behavior and different forms of sexual activity. ${ }^{1,2}$ Consequently, workplace relationships that entail any form of sexual activity have been portrayed through negative rather abhorred - connotations and destructive effects such as sexual exploitation and harassment, litigations, cynicism, disapproval from colleagues, and negative publicity. $2,6,7,21,22$

However, following Wilson, ${ }^{2}$ we argue that the literature that only focuses on the destructive effects of workplace romance is founded on the notion which portrays organizations as enforcing instrumental rationality, control, and the suppression of emotions. We argue that such a negative conceptualization of workplace romance is based on a restrictive view that assumes romantic relations to be utilitarian sexual relations and portrays them as inherently destructive for employee behaviors and performance.

Additionally, workplace romance literature mainly focuses on sexual relations, forced sex, and sexual behavior. ${ }^{6,8,13,21,23,24}$ The definition of workplace romance by Quinn ${ }^{5}$ (p. 30) "relationship between two members of the same organization that is perceived by a third party to be characterized by sexual attraction" is indicative of such a focus of the literature. In doing so, the literature has not exclusively focused on committed romantic relationships. Moreover, as noted by Khan et al, such a conceptualization of workplace romance has created issues that are particularly relevant to the operationalization of the concept. ${ }^{1}$

Moreover, the literature has used a single-item measure. ${ }^{13,23}$ Pierce and Aguinis ${ }^{23}$ measured workplace romance by asking the respondents to report their involvement in workplace romance by responding to the single-item measure - "I am currently romantically involved with (e.g., dating, married to) a member of my organization (1=Yes, $0=$ No)". Salvaggio et al used third-party reports and the single-item measure - "Have you ever observed a romance at your current workplace?" $(1=$ Yes, $0=\mathrm{No}) "$ - to measure workplace romance. ${ }^{13}$ We follow Khan et al to suggest that the single-item measure of workplace romance limits the workplace romance to sexual or romance-related activities such as dating, hugging, or kissing. ${ }^{1}$ These measures do not capture the intensity of love, passion, or the level of commitment involved in the relationship. Similarly, these measures cannot foreground the future intention of romantically involved participants and the future of their relationship. The problem is more evident in the third-party romance reports, as the observer can observe and witness only a few of the clearly visible aspects of the relationship such as kissing or hugging. Thus, we propose the need to revisit the concept of workplace romance and its relationship and measures to bring to the fore the intensity, depth, and commitment involved in workplace romantic relationships and its performance and behavioral outcomes. Moreover, building on Khan et al, we expect that a consensual and committed workplace romantic relationship can have positive effects on employee behaviors and performance outcomes. ${ }^{1}$

We acknowledge that romantic relations in the workplace can have detrimental consequences for organizations and employees. However, we argue that romantic relations can have different motives such as ego satisfaction, exploitation, sexual intercourse, and long-term committed love relationships. ${ }^{2,425,26}$ The effects may vary depending on the motive to involve in the relationship. ${ }^{2,4}$ The effect of consensual and committed relations on the behavior of romance participants is usually positive ${ }^{1,4}$ According to Hatfield and Sprecher ${ }^{27}$ (p. 387), "the joy of love generally spills over and adds sparkle to everything else in life". ${ }^{27}$ Thus, we propose that there can be an alternative - constructive side - particularly in mutually welcomed and committed workplace romances. ${ }^{4,25}$

Furthermore, the impression management hypothesis suggests that participants in a workplace romance work hard to improve their performance in order to counteract any negative perceptions and repercussions related to their involvement in workplace romances. ${ }^{23,28}$ Moreover, the literature provides empirical support to the impression management hypothesis by revealing a positive relationship between workplace romance and employee performance. ${ }^{1,23}$ Similarly, the happy/productive worker hypothesis also suggests that workplace romance can have positive effects on employee job performance.

Finally, the general romantic relationship literature suggests that committed romantic relationships and their manifestations in the form of love, long-term commitment, dating, affectionate touch, and kissing positively affect the behaviors and life satisfaction of romance participants. ${ }^{4,25,29,30}$ Thus, we follow the constructive effect premise of workplace romance to develop the following hypothesis.

Hypothesis 1: workplace romance will be positively related to employee job performance.

\section{Affective commitment as a mediator of the relationship between workplace romance and employee job performance}

A number of studies have suggested a positive relationship between workplace romance and affective commitment. ${ }^{6,10,11,23}$ 
Workplace romantic relationships create a happy and relaxed environment that can lead to affective feelings for coworkers and the organization. ${ }^{7}$ Pierce and Aguinis ${ }^{23}$ argue that positive emotions experienced in romantic relations can have affective spillover effects in the form of emotional bonding with organization and coworkers. Kark ${ }^{31}$ suggests that intimate relationships can create emotional bonding with leaders, colleagues, and organization. The positive experience of romantic relation creates feelings of affection toward the organization and organizational members that may be reciprocated and shape an organizational culture based on mutual affection, love, and commitment. 7,9,11 Emotional bonding refers to a committed long-term and stable relationship that includes a sense of belongingness, a sense of security, care and warmth, heartfelt emotions, and mutual interaction. ${ }^{32}$ Thus, it is likely that committed romantic relationships positively contribute to the affective commitment of romance participants to the organization, coworkers, and supervisors.

Additionally, a plethora of studies have theorized and provided empirical evidence about a positive relationship between affective commitment and employee job performance. ${ }^{15,33,34}$ Sharma and Dhar ${ }^{33}$ show that affectively committed employees perform beyond the expected performance standards. Seen in this light, the affective commitment of health-care professionals is particularly important, as affection toward organization, profession, and patients is a key aspect of the quality of health-care services and patient satisfaction. ${ }^{33}$

Literature shows that affectively committed employees are pro-social and develop affective relationships with coworkers, seniors, subordinates, and organization. ${ }^{16,17}$ Affectively committed employees demonstrate voluntary knowledge sharing and joint problem-solving behavior that lead to improved performance. ${ }^{16,17,32}$ In essence, workplace romances give rise to emotional reactions that can create emotional bonding - affective commitment - with the organization, supervisors, and coworkers - that are likely to positively contribute to improved performance. Thus, we propose that affective commitment mediates the effect of lateral workplace romance on employee performance.

According to Wasti and Can, ${ }^{15}$ we understand that workplace romance affects different foci of affective commitment - affective coworker commitment, affective supervisor commitment, and affective organizational commitment - that in turn are positively related to employee performance. Moreover, we followed Wasti and $\mathrm{Can}^{15}$ to use them as parallel mediators of the relationship between workplace romance and employee performance. This informs the following hypotheses.
Hypothesis 2: affective coworker commitment, affective supervisor commitment, and affective organizational commitment act as parallel mediators to significantly mediate the relationship between workplace romance and employee job performance.

\section{Moderated mediation - culture as a moderator}

National culture can significantly influence workplace romance and its effects on employee work-related behaviors and performance because it plays a vital role in shaping individuals' attitudes and behaviors and the dynamics of their social relationship. ${ }^{18,35}$ Culture is one of the important factors that shape individuals' thoughts, feelings, behaviors, and romantic relationships. ${ }^{18}$ Romantic relationships may be approved or disapproved in a culture depending on its social organization and ideology. ${ }^{35}$ Several scholars have extensively used Hofstede's ${ }^{36}$ cultural dimensions such as individualism and collectivism to study the dynamics of the general romantic relationship in different cross-cultural studies. ${ }^{37-43}$ These studies show that individual attitudes toward romance and romantic relationship behaviors are different in individualistic and collectivist cultures. ${ }^{39,43}$ Although both Chinese and Pakistani culture are high on Hofstede's ${ }^{36}$ collectivist cultural dimension, the difference in these cultures can be established in several ways. Family values in both Chinese and Pakistani cultures are strong. ${ }^{24,44}$ However, close relationships in Chinese culture extend beyond family to include the Guanxi - a wider network of relationship - whose support and maintenance is one of the key priorities both in general social life and work life. Therefore, in terms of workplace romance, Chinese employees ensure that their workplace romance partner's face is respected to avoid any harm to their wider network of social relations as a part of Guanxi.

Additionally, the literature suggests that cultural variations in the form of social, economic, and technological developments as well as ethnocultural diversity explain the difference in experiences of workplace romance and its effects on employee behavioral and performance outcomes of workplace romance. ${ }^{19,20}$ Rapid technological and economic development, globalization, and modern tools of communication have shaped the new outlook of Chinese society with a liberal worldview toward romantic relationships and sexuality. ${ }^{18}$ Romantic relationship and sexuality are no longer taboo in People's Republic of China.

On the other hand, the strong family institution as well as cultural, religious, and societal taboos in Pakistani culture may not provide enough space for romantic relationships, 
particularly at the workplace. ${ }^{44}$ Although globalization and economic integration have had significant impact on women's development and enhanced participation of women at the workplace in Pakistan, women's freedom and respect in male-dominant national and workplace cultures remain skewed. ${ }^{45,46}$ Therefore, although we follow Khan et al who showed a positive relationship between workplace romance and performance for a sample of doctors working in Pakistan, we propose that culture moderates the relationship between workplace romance and employee performance, where the relationship is stronger in the People's Republic of China. ${ }^{1}$

Hypothesis 3: national culture moderates the indirect relationship between workplace romance and employee performance, where the relationship is stronger in the People's Republic of China.

\section{Methods \\ Data collection and analysis}

We collected two-waved survey data from 312 (64\% return rate) paramedical staff working in six Chinese and seven Pakistani public-sector hospitals. Of the 312 respondents, 162 were from Pakistan and 150 from the People's Republic of China. The sample included 174 males and 138 females. The average age of the respondents was 36 years and the average work experience was 6.54 years. Before starting the survey, we tested the questionnaire in a pilot study with 20 respondents and five academicians.

Initially, we contacted 1,000 paramedical staff in person and provided them with an information sheet that contained information about the purpose of the study, the definitions of the constructs of the study, and a promise of confidentiality. In addition, the information sheet contained participation criteria that included the following three questions. Are you currently involved in a workplace romance? Are you willing to participate in the two rounds of the survey? Would you introduce us to your immediate supervisors to gain some information about your general job performance? After several reminders and requests, 392 paramedical staff responded positively about participating in the survey.

The purpose of data collection in two waves was to reduce the common method bias. A code was placed on each questionnaire to match the data collected in different rounds and from different sources. The present study was conducted as a part of a project that was aimed to examine different forms of social relations and social capital, including bonding capital, bridging capital, and friendship and workplace romance. In the first round, data about workplace romance and other forms of social relations were collected. Data about age, tenure, culture, type of romantic relations (heterosexual/homosexual and hierarchical/lateral) were also collected in the first round. In accordance with Chan et al, we used the nationality of respondents as a proxy measure for national culture. ${ }^{47}$ Data about romance type were collected by asking the respondents whether they were involved in heterosexual or homosexual romance, and, then, whether they were involved in a hierarchical or lateral romance. Data about culture were collected by asking the respondents about their nationality. In total, 355 employees responded in the first round.

After 3 months, data about the mediators (the foci of affective commitment) were collected, and 340 employees responded in the second round. Data about the outcome variable (job performance) were based on the supervisors' perception of the respondent's performance. Supervisor performance ratings are viewed to be more accurate and reliable than self-ratings. ${ }^{48}$ In total, 141 supervisors (immediate bosses) rated the performance of respondents who had responded in both the data collection rounds. One supervisor, on average, rated the performance of 2.41 respondents (ranging from one to four respondents). The first and second waves of data collection took place in January 2017 and May 2017 , respectively. Supervisors rated the performance of the respondents who responded in both the data collection waves in June 2017. In addition, data from two different sources reduces common method bias. ${ }^{49}$ Moreover, we used already developed and validated measurement scales for all the variables of our study. Overall, we received 320 responses that matched both data collection rounds and sources. Eight responses were discarded due to missing data. Therefore, 312 responses (162 from Pakistan and 150 from People's Republic of China) were used in data analysis.

We used AMOS 24.0 for data analysis. SEM and bootstrapping were used to test the hypotheses. To evaluate the goodness of fit of our measurement and structural models, we adopted chi-square statistic $(\chi 2), \chi^{2 / d f}$, the root mean square error of approximation (RMSEA), Tucker-Lewis Index (TLI), and the comparative fit index (CFI) ${ }^{49}$

\section{Ethics/copyright}

The protocol was approved by the employee councils of the participating organizations as well as the ethics committees of the School of Management, Jiangsu University, Zhenjiang, People's Republic of China, and the Department of Management Sciences, COMSATS University, Islamabad, Lahore Campus, Lahore, Pakistan. All participants gave written informed consent. 


\section{Measures and variables}

We adapted a seven-item scale $(\alpha=0.91)$ from Rusbult et al ${ }^{50}$ to measure workplace romance. The scale measures the commitment level of the romance participants. We used this scale, as we understand romantic relations to be consensual and committed relations. ${ }^{1,6,50}$ "I want my relationship with my colleague to last for a very long time" and "I am committed to maintaining my relationship with my colleague" are examples of the scale items. The responses were measured on five points ranging from 1 (strongly disagree) to 5 (strongly agree).

Affective - organizational, coworkers, and supervisor - commitment scales $(\alpha>0.70)$ were adopted from Wasti and Can. ${ }^{15}$ All three adopted scales for measuring affective commitment comprised five items. "I would be very happy to spend the rest of my career with my current co-workers" and "I really feel as if my co-worker's problems are my own" are examples of the items of the scale that we used to measure affective coworker commitment. "I would be very happy to spend the rest of my career with my current supervisor" and "I really feel as if my supervisor's problems are my own" are examples of the items of the scale that we used to measure affective supervisor commitment. "I would be very happy to spend the rest of my career with this organization" and "I really feel as if this organization's problems are my own" are examples of the items of the scale that we used to measure affective organizational commitment. The responses were measured on five points ranging from 1 (strongly disagree) to 5 (strongly agree).
To measure job performance, a four-item scale $(\alpha=0.86)$ was adapted from Baird. " ${ }^{48}$ "How do you evaluate his/her work effort?" and "How do you evaluate the quantity of his/her work?" are examples of the scale items. Job performance was measured on a five-point scale from 1 (performance below the minimum acceptable level) to 5 (performance consistently far exceeded expectations). The scale items of all the variables are presented in Table 1.

\section{Control variables}

Hierarchical and lateral workplace romances are argued to have different effects on employee work-related behaviors and performance. ${ }^{7,10}$ However, our data show that 11 of the respondents were involved in hierarchical (with a subordinate or a supervisor) workplace romances. Therefore, hierarchical/ lateral romances may not confound our results. Moreover, the literature suggests that homosexual romances are more detrimental than heterosexual romances. ${ }^{2,6}$ The sample used in this study shows little variance in terms of homosexual/ heterosexual romances as only seven out of 312 reported involvement in a homosexual relationship. Therefore, heterosexual/homosexual romances may not confound our results. Thus, we did not control for romance types (hierarchical/ lateral and heterosexual/homosexual).

Furthermore, age, gender, and work experience can confound the results. ${ }^{1,6,7}$ However, age and experience are highly correlated $(r=0.88, p<0.01)$ in our sample data. We intended to use work experience as a control variable, because we perceive that work experience has more relevance as far

Table I Scale items

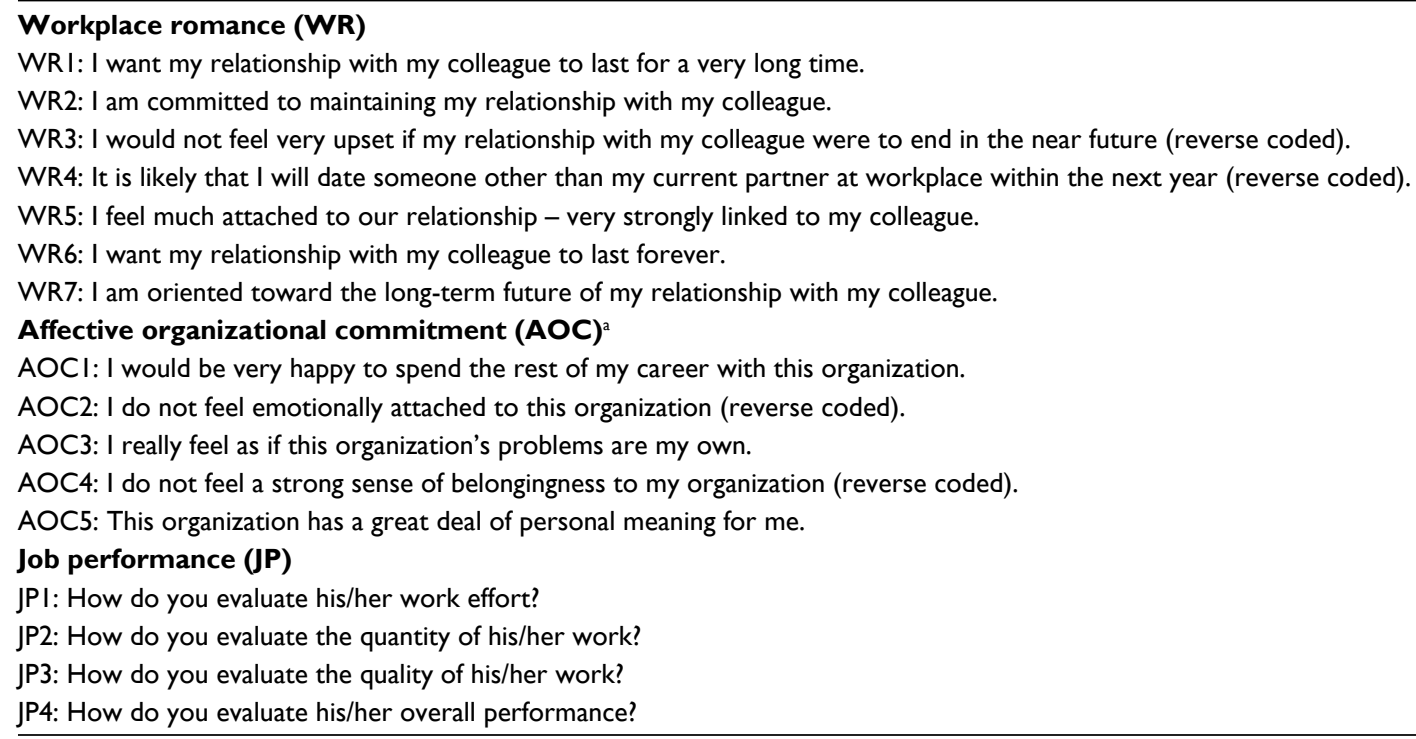


as its effect on employee job performance is concerned. However, as Table 1 depicts, the correlation of work experience with the outcome variable - job performance - is not significant. Thus, following Becker, we did not control for work experience. Similarly, the correlation between gender and job performance is not significant. ${ }^{51}$ Therefore, we followed Becker and did not control for gender. ${ }^{51}$

\section{Results}

\section{Means and correlations}

Means, SDs, and correlations among the constructs are presented in Table 2.

\section{Measurement models}

We used confirmatory factor analysis to test the model fitness with the data. Our measurement Model 1 comprised five latent constructs - workplace romance (WR), affective organizational commitment (AOC), affective supervisor commitment (ASC), affective coworker commitment (ACC), and employee job performance (JP) - and 27 observed variables. The observed variables (WR3, ASC3, and AOC5) that showed suboptimal loading or high correlation with other items were dropped. The fit indices (after dropping the problematic items) $-\chi 2=324.976, \mathrm{df}=220, \chi 2 / \mathrm{df}=1.477, \mathrm{GFI}=0.92$, $\mathrm{IFI}=0.977$, TLI $=0.972, \mathrm{CFI}=0.977$, and RMSEA $=0.039$ - show that the model has a very good fit with the data. The standardized outer loadings shown in Figure 1 were significant $(p<0.001)$.

Moreover, as the aim of the study was also to test the moderating effect of culture on the interrelationships between workplace romance, affective commitment, and employee job performance, CFA was conducted for the cultures of the two countries - Pakistan and People's Republic of China - in measurement model 2. In addition, the items retained in the measurement Model 1 were retained in the measurement model 2 for both the countries - Pakistan and People's Republic of China - as they showed significant loading $(p<0.001)$. The fit indices $-\chi 2=594.018, \mathrm{df}=440$, $\chi 2 / \mathrm{df}=1.35, \mathrm{GFI}=0.87, \mathrm{IFI}=0.961, \mathrm{TLI}=0.955, \mathrm{CFI}=0.961$, and RMSEA $=0.034$ - show that the model has a good fit with the data.

Cronbach's $(\alpha)$ values, composite reliability (CR), maximum shared variance (MSV), average variance extracted (AVE), and average shared variance (ASV) of WR, AOC, ASC, ACC, and JP for the measurement models 1 and 2 are presented in Table 3. The values of Cronbach's $\alpha>0.70$ (Table 3) and $C R>0.70$ (Table 3) show that the internal consistency and reliability are satisfactory, respectively. Further, convergent validity is satisfactory with AVE values $>0.50$ (Table 3).

Discriminant validity was examined using the FornelLacker test. The square root values of AVE (on the diagonal of columns 2-6 in Table 3) of WR, ACC, ASC, and AOC (Table 3) are greater than correlations of their inter-constructs (values other than on the diagonals columns 2-6 in Table 3). In addition, ASV and MSV < AVE. Thus, the discriminant validity of all the measurement scales is satisfactory.

\section{Structural model}

To evaluate the structural Model 1, we first tested the direct effect of workplace romance on employee job performance. The direct effect of workplace romance $(\beta=0.216, p<0.001)$ was found to be significant. The indices of this initial Model $1-\chi 2=72.751, \mathrm{df}=34, \chi 2 / \mathrm{df}=2.14, \mathrm{GFI}=0.956, \mathrm{IFI}=0.981$, TLI $=0.975$, CFI $=0.981$, and RMSEA $=0.061-$ showed that the model has a very good fit with the data. Thus, Hypothesis 1 - "workplace romance will be positively related to employee job performance" - is supported.

In Model 2 presented in Figure 1, we included three parallel mediators - affective coworker commitment, affec-

Table 2 Means and correlations

\begin{tabular}{|c|c|c|c|c|c|c|c|c|c|c|}
\hline Construct & Means & SD & $\mathbf{I}$ & 2 & 3 & 4 & 5 & 6 & 7 & 8 \\
\hline I. WR & 3.54 & 0.91 & & & & & & & & \\
\hline 2. ACC & 3.71 & 0.86 & $0.18^{* *}$ & & & & & & & \\
\hline 3. ASC & 3.69 & 0.88 & $0.20 * *$ & $0.36 * *$ & & & & & & \\
\hline 4. AOC & 3.70 & 0.87 & $0.17 * *$ & $0.40 * *$ & $0.40 * *$ & & & & & \\
\hline 5. JP & 3.64 & 0.88 & $0.20 * *$ & $0.42^{* *}$ & $0.42 * *$ & $0.59 * *$ & & & & \\
\hline 6. Culture & 1.48 & 0.50 & $-0.65^{* *}$ & -0.09 & $-0.15^{* *}$ & $-0.13^{*}$ & $-0.19 * *$ & & & \\
\hline 7. Gender & 1.45 & 0.50 & -0.02 & 0.02 & 0.002 & -0.04 & 0.02 & 0.10 & & \\
\hline 8. Age & 35.80 & 6.68 & $0.18^{* *}$ & 0.05 & 0.09 & 0.10 & 0.11 & $-17 * *$ & 0.06 & \\
\hline 9. Experience & 6.64 & 4.83 & 0.10 .009 & 0.03 & 0.09 & 0.09 & 0.11 & -0.04 & 0.050 & $0.88 * *$ \\
\hline
\end{tabular}

Note: $\mathrm{n}=3 \mid 2,{ }^{*}<<0.05,{ }^{*} p<0.01$ level (two-tailed).

Abbreviations: WR, workplace romance; ACC, affective colleague commitment; ASC, affective supervisor commitment; AOC, affective organizational commitment; JP, job performance. 


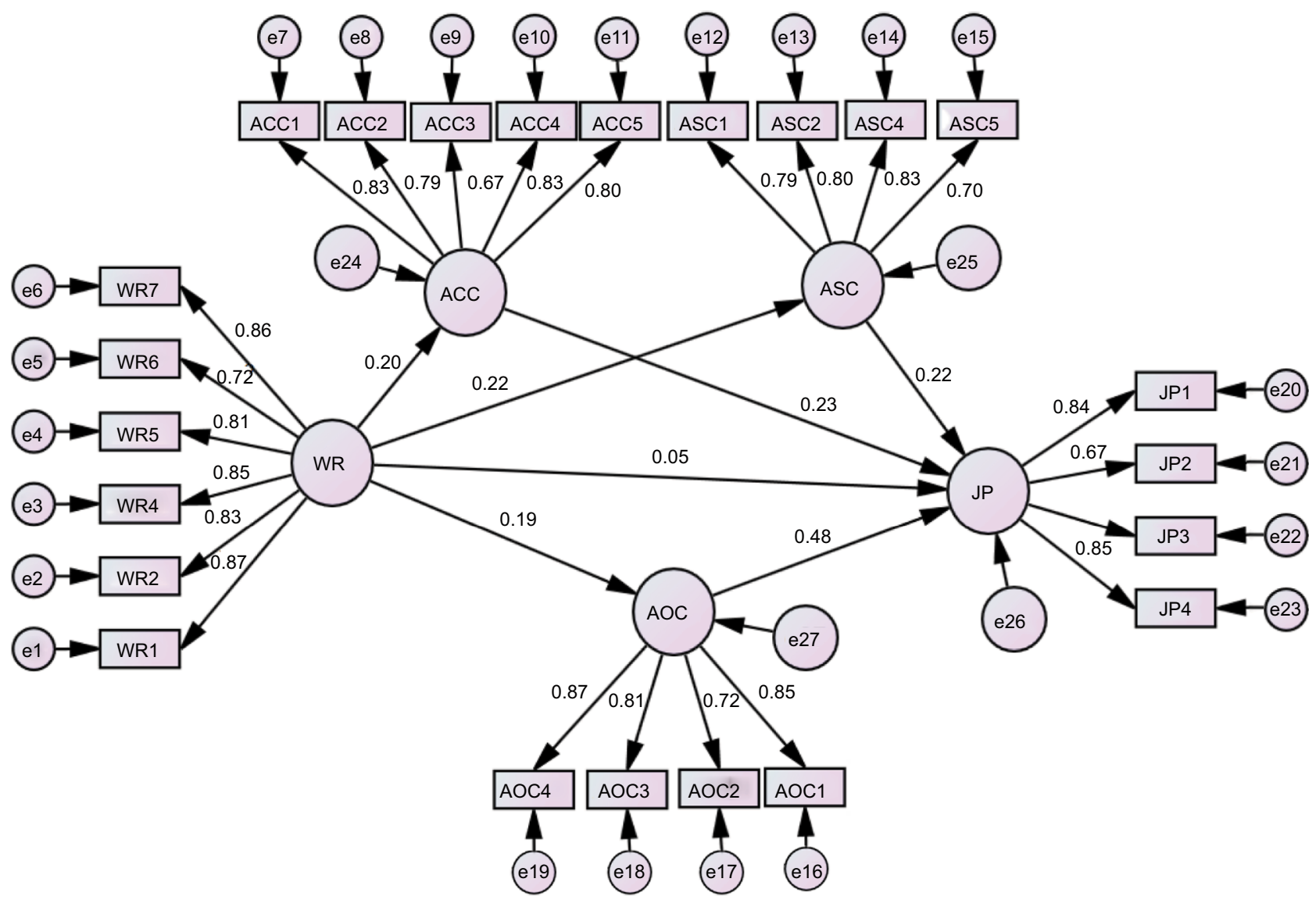

Figure I Structural Model 2 - Mediation model: this model shows the mediation of the relationship between work romance and employee job performance through three foci of affective commitment.

Abbreviations: WR, workplace romance; ACC, affective colleague commitment; ASC, affective supervisor commitment; AOC, affective organizational commitment; JP, job performance.

Table 3 Discriminant validity, convergent validity, and internal consistency

\begin{tabular}{|c|c|c|c|c|c|c|c|c|c|c|}
\hline $\begin{array}{l}\text { Construct } \\
\text { overall }\end{array}$ & I & 2 & 3 & 4 & 5 & $\alpha$ & CR & AVE & MSV & ASV \\
\hline I.WR & 0.82 & & & & & 0.93 & 0.93 & 0.68 & 0.05 & 0.04 \\
\hline 2. ACC & 0.19 & 0.79 & & & & 0.89 & 0.89 & 0.62 & 0.22 & 0.15 \\
\hline 3. ASC & 0.21 & 0.39 & 0.78 & & & 0.89 & 0.86 & 0.61 & 0.20 & 0.14 \\
\hline 4. AOC & 0.17 & 0.44 & 0.40 & $0.8 I$ & & 0.88 & 0.89 & 0.66 & 0.37 & 0.19 \\
\hline 5. JP & 0.22 & 0.47 & 0.45 & 0.61 & 0.80 & 0.87 & 0.88 & 0.64 & 0.37 & 0.21 \\
\hline \multicolumn{11}{|l|}{ Pakistan } \\
\hline I. WR & 0.71 & & & & & & 0.86 & 0.50 & 0.02 & 0.01 \\
\hline 2. ACC & 0.06 & 0.77 & & & & & 0.88 & 0.60 & 0.24 & 0.12 \\
\hline 3. ASC & 0.15 & 0.37 & 0.77 & & & & 0.85 & 0.59 & 0.17 & 0.11 \\
\hline 4. AOC & 0.03 & 0.33 & 0.33 & 0.83 & & & 0.90 & 0.69 & 0.21 & 0.11 \\
\hline 5. JP & 0.05 & 0.49 & 0.41 & 0.46 & 0.77 & & 0.86 & 0.60 & 0.24 & 0.16 \\
\hline \multicolumn{11}{|c|}{ People's Republic of China } \\
\hline I. WR & 0.77 & & & & & & 0.90 & 0.59 & 0.06 & 0.04 \\
\hline 2. ACC & 0.24 & 0.79 & & & & & 0.89 & 0.63 & 0.27 & 0.17 \\
\hline 3. ASC & 0.14 & 0.37 & 0.80 & & & & 0.87 & 0.64 & 0.21 & 0.14 \\
\hline 4. AOC & 0.19 & 0.52 & 0.43 & 0.79 & & & 0.87 & 0.63 & 0.56 & 0.26 \\
\hline 5. JP & 0.16 & 0.45 & 0.46 & 0.75 & 0.82 & & 0.89 & 0.67 & 0.56 & 0.25 \\
\hline
\end{tabular}

Note: Bold values $=\sqrt[2]{\mathrm{AVE}}$

Abbreviations: WR, workplace romance; ACC, affective colleague commitment; ASC, affective supervisor commitment; AOC, affective organizational commitment; JP, job performance; AVE, average variance extracted; MSV, maximum variance shared; ASV, average variance shared; CR, composite reliability; $a$, Cronbach's alpha. 
tive supervisor commitment, and affective organizational commitment. The fit indices $-\chi 2=454.196, \mathrm{df}=245, \chi 2 /$ $\mathrm{df}=1.854$, GFI $=0.892$, IFI $=0.953$, TLI $=0.947, \mathrm{CFI}=0.953$, and RMSEA $=0.052$ - show that the model has a good fit with the data. These results suggest that the role of affective coworker commitment, affective organizational commitment, and affective supervisor commitment as parallel mediators is important in the relationship between workplace romance and employee performance.

The significance of the role of parallel mediators affective coworker commitment, affective organizational commitment, and affective supervisor commitment - in the relationship between workplace romance and employee performance was tested using AMOS bootstrapping by specifying a sample of 2,000 . The results obtained through bootstrapping are shown in Table 4.

Table 4 shows that, after the inclusion of the parallel mediators, the direct effect of workplace romance on an employee's job is non-significant whereas the indirect of workplace romance on job performance is significant. Moreover, the effect of a control variable (evident from Figure 1) on job performance is non-significant. Thus, it is concluded that, as parallel mediators, affective coworker commitment, affective organizational commitment, and affective supervisor commitment fully mediate the positive relationship between workplace romance and employee performance. Thus, Hypothesis 2 is supported.

\section{Moderated mediation - the moderating role of culture}

To test the moderating effect of culture in an indirect effect on workplace romance on employee job performance, a

Table 4 Direct and indirect effects and $95 \% \mathrm{Cls}$

\begin{tabular}{llll}
\hline Parameter & Estimate & Lower & Upper \\
\hline Model 2 - Mediation Model & & & \\
Direct effects & & & \\
ACC $<---$ WR & $0.20 I^{*}$ & 0.058 & 0.354 \\
ASC $<---$ WR & $0.22 I^{*}$ & 0.083 & 0.363 \\
AOC $<---$ WR & $0.188^{*}$ & 0.052 & 0.327 \\
JP <---- WR & 0.055 & -0.057 & 0.172 \\
JP <--- ACC & $0.230^{*}$ & 0.103 & 0.366 \\
JP <--- ASC & $0.216^{*}$ & 0.078 & 0.343 \\
JP <--- AOC & $0.48 I^{*}$ & 0.331 & 0.616 \\
Indirect effects & & & \\
JP <-- ACC, ASC, AOC <-- WR & $0.184^{*}$ & 0.078 & 0.286 \\
\hline
\end{tabular}

Note: *Empirical $95 \% \mathrm{Cl}$ does not overlap with zero.

Abbreviations: WR, workplace romance; ACC, affective colleague commitment; ASC, affective supervisor commitment; AOC, affective organizational commitment; JP, job performance. $\chi 2$ difference test was used. For this purpose, multigroup analysis with bootstrapping (specifying a sample of 2,000 at a 95\% CI) was conducted using AMOS 24.0. Data were divided into two groups - Pakistan and People's Republic of China. The multigroup function in AMOS estimates the $\chi^{2}$ difference between the constrained (all paths of interest are constrained for the equality of structural weights) and unconstrained models. The comparison showed that the $\chi 2$ difference between the unconstrained $(\chi 2=691.033, \mathrm{df}=446)$ and constrained $(\chi 2=738.775, \mathrm{df}=471)$ models was significant $(\chi 2$ difference $=47.742$, df difference $=25, p \leq 0.01$ ), suggesting that culture moderates the indirect effect of workplace romance on employee job performance. The fit indices $-\chi 2=691.033$, $\mathrm{df}=446, \chi 2 / \mathrm{df}=1.549, \mathrm{GFI}=0.85, \mathrm{IFI}=0.938, \mathrm{TLI}=0.929$, $\mathrm{CFI}=0.938$, and RMSEA $=0.042-$ showed that the model has a good fit with the data.

Bootstrapping results presented in Table 5 show that the three parallel mediators fully mediate the relationship between workplace romance and employee job performance for the Chinese sample whereas, in the Pakistani sample, these mediators do not mediate the relationship between workplace romance and employee job performance. Therefore, we conclude that culture moderates the indirect

Table 5 Direct and indirect effects and $95 \% \mathrm{Cls}$

\begin{tabular}{llll}
\hline Parameter & Estimate & Lower & Upper \\
\hline Moderated mediation - Pakistan & & & \\
Direct effects & & & \\
ACC <--- WR & 0.074 & -0.107 & 0.264 \\
ASC <--- WR & 0.151 & -0.052 & 0.378 \\
AOC <--- WR & 0.046 & -0.136 & 0.214 \\
JP <----- WR & -0.014 & -0.258 & 0.277 \\
JP <---- ACC & $0.366^{*}$ & 0.170 & 0.561 \\
JP <---- --ASC & $0.211^{*}$ & 0.012 & 0.438 \\
JP <---- AOC & $0.316^{*}$ & 0.129 & 0.531 \\
Indirect effects & & & \\
JP <-- ACC, ASC, AOC <-- WR & 0.075 & -0.036 & 0.220 \\
Moderated mediation: People's Republic of China & & \\
Direct effects & & & \\
ACC <--- WR & $0.255^{*}$ & 0.061 & 0.450 \\
ASC <--- WR & $0.157^{*}$ & -0.045 & 0.350 \\
AOC <--- WR & $0.217^{*}$ & 0.021 & 0.419 \\
JP <----- WR & -0.019 & -0.176 & 0.135 \\
JP <---- ACC & $0.105^{*}$ & -0.053 & 0.295 \\
JP <---- ASC & $0.198^{*}$ & 0.020 & 0.376 \\
JP <--- --AOC & $0.685^{*}$ & 0.503 & 0.827 \\
Indirect effects & & & \\
JP <-- ACC, ASC, AOC <-- WR & $0.207^{*}$ & 0.025 & 0.395 \\
\hline Note * W & &
\end{tabular}

Note: *Empirical $95 \% \mathrm{Cl}$ does not overlap with zero.

Abbreviations: WR, workplace romance; ACC, affective colleague commitment; ASC, affective supervisor commitment; AOC, affective organizational commitment; $\mathrm{JP}$, job performance. 
relationship between workplace romance and employee job performance. Thus, Hypothesis 3 is supported.

\section{Discussion and conclusion}

\section{Theoretical contributions}

This study first examined the relationship between workplace romance and employee job performance and then tested the mediating role of three foci of affective commitment in this relationship. Based on a two-wave survey data collected from 312 paramedical staff from Pakistani and Chinese publicsector hospitals, our study shows that mutually consensual and committed workplace romance is positively related to employee job performance. This result is consistent with the research that emphasizes the importance of constructive aspects and outcomes of workplace romance for employee work-related attitudes and behaviors. . $5,6,10,11^{\text {The finding }}$ supports the theories proposed by Quinn, Cole, Pierce et al, and Wright and Cropanzano who suggested that workplace romance can improve employee job performance. ${ }^{5-7,12}$ For example, Cole suggested that, having satisfied their companionship needs, participants of workplace romance can have more time and energy available to perform their jobs and that can improve their job performance. ${ }^{7}$ Pierce et al proposed the impression management hypothesis which suggests that participants of a workplace romance work hard to improve their performance to counter any negative perceptions arising because of their involvement in workplace romances. ${ }^{6}$ Wright and Cropanzano's happy/productive worker hypothesis also suggests a positive relationship between workplace romance and employee job performance. ${ }^{12}$ Our finding is also in line with that of Khan et al, who empirically showed that consensual and committed workplace romantic relationships are positively related to employee job performance. ${ }^{1}$

However, the finding contradicts results reported by Salvaggio et al and Baker who suggested that workplace romances can have destructive effects on the participants of workplace romance in the form sexual exploitation, harassment, litigations, stress, and negative publicity and can negatively affect employee job performance. ${ }^{8,13}$ This difference in findings can be attributable to the reason that our findings are mainly based on lateral intact workplace romances (our sample comprised only 11 hierarchical workplace romances) whereas destructive effects are usually linked with hierarchical and dissolved workplace romances.

As an important addition to previous studies such as those by Pierce and Aguinis, Cole, Biggs et al, and Khan et al, we introduced the three foci of affective commitment as three parallel mediators of the relationship between workplace romance and employee performance. ${ }^{1,7,11,23}$ The results revealed that affective commitment foci fully mediate the relationship between workplace romance and employee job performance. Thus, our study extends the workplace romance literature by showing that workplace romance, in the form of a consensual and committed relationship, is positively related to the three foci of affective commitment that, in turn, positively contribute to employee job performance. This contribution is not only important because it brings to the fore the significant role of workplace romance in employee performance and in making them affectively committed to coworkers and supervisors, but also because it can be linked with other work-related attitudes and behaviors such as turnover intentions and overall productivity. $2,6,12,52$

The key addition to the literature on workplace romance is the cross-cultural comparison of the interrelationships between workplace romance, affective commitment foci, and employee job performance. To the best of our knowledge, this is the first study that has examined the moderating role of national culture on the interrelationships between workplace romance, affective commitment foci, and employee job performance. In this light, our study suggests that cultural values and belief system can be an important influence on the workplace romance experiences as well as on employee work-related behaviors and performance outcomes. The finding supports theories which suggest that technological and economic development, globalization, and modern tools of communication have made Chinese society liberal as far as its views toward romantic relationships and sexuality are concerned. ${ }^{18-20}$ Similarly, the finding seems to support the argument that strong family institution as well as cultural, religious, and societal taboos may not provide enough space for romantic relationships, particularly at the workplace. ${ }^{44}$

\section{Practical implications}

Our study suggests that workplace romance should not be a necessarily problematic and disorderly factor for employee behaviors and performance. That is, managers can see workplace romance - the consensual and committed relationship - as an antecedent of affective commitment that can lead to improved employee job performance. Paramedical staff deal with human life and, if workplace romantic relations can make them affectively committed to their workplace, coworkers, and supervisors as well as improve their performance, it can contribute to better health-care service provision. However, as our study is not without limitations, the practical implications should not be seen in isolation from the limitations presented in the following subsection. 


\section{Limitations and future research}

Our findings need careful attention, as workplace romance may not be consistent with ethical, moral, societal, and religious guidelines and norms..$^{21,26}$ Our findings are based on a small sample that is limited to the health-care sector. Future studies based on larger samples from different contexts and industries can enhance our understanding of workplace romance and the discourse on its effects. Workplace romance outcomes can be different for professions and organizations. Another limitation of our study is that we focused only on intact workplace romances; we did not study dissolved workplace romances and extramarital romances that are argued to be detrimental for different work-related behaviors and employee performance. ${ }^{9}$ If workplace romance is dissolved, if can negatively affect employee wellbeing and commitment and can have detrimental effects on employee job performance. Moreover, workplace romance as an extramarital affair can also be an important area for future studies.

\section{Author contributions}

Muhammad Aamir Shafiq Khan, Tehseen UL Mushtaq, Ahmed Abdul Hameed, and Muhammad Usman designed this study. Muhammad Aamir Shafiq Khan, Tehseen UL Mushtaq, and Du Jianguo collected and analyzed data. Muhammad Aamir Shafiq Khan, Ahmed Abdul Hameed, and Muhammad Usman wrote the English version of this manuscript. Du Jianguo participated in drafting the paper and revised it critically for important intellectual content. All authors contributed toward data analysis, drafting and revising the paper, and agree to be accountable for all aspects of the work.

\section{Disclosure}

The authors report no conflicts of interest in this work.

\section{References}

1. Khan MAS, Jianguo D, Usman M, Ahmad MI. Moderated mediation model of interrelations between workplace romance, wellbeing, and employee performance. Front Psychol. 2017;8:2158.

2. Wilson F. Romantic relationships at work: why love can hurt. Int $J$ Manag Rev. 2015;17(1):1-19.

3. Mainiero LA, Jones KJ. Sexual harassment versus workplace romance: social media spillover and textual harassment in the workplace. Acad Manag Perspect. 2013;27(3):187-203.

4. Diamond LM, Savin-Williams RC, Dubé EM. Sex, dating, passionate friendships, and romance: intimate peer relations among lesbian, gay, and bisexual adolescents. In: Furman W, Brown BB, Feiring C, editors. The Development of Romantic Relationships in Adolescence. New York: Cambridge University Press; 1999:175-201.

5. Quinn RE. Coping with cupid: the formation, impact, and management of romantic relationships in organizations. Adm Sci Q. 1977:30-45.

6. Pierce CA, Byrne D, Aguinis H. Attraction in organizations: a model of workplace romance. J Organ Behav. 1996;17(1):5-32.
7. Cole N. Workplace romance: a justice analysis. J Bus Psychol. 2009;24(4):363-372.

8. Baker AN. Antecedents and consequences of observing workplace sexual behavior. J Manag Psychol. 2016;31(1):265-279.

9. Powell GN, Foley S. Something to talk about: romantic relationships M organizational settings. J Manag. 1998;24(3):421-448.

10. Davis J. Title VII and the workplace romance. Mun Law. 2012;53:6-10.

11. Biggs D, Matthewman L, Fultz C. Romantic relationships in organisational settings: Attitudes on workplace romance in the UK and USA. Gender Manag Int J. 2012;27(4):271-285.

12. Wright TA, Cropanzano R. The happy/productive worker thesis revisited. In: Kane-Frieder RE, Hochwarter WA, Hampton HL, Ferris GR, editors. Research in Personnel and Human Resources Management. Bingley: Emerald Group Publishing Limited; 2007:269-307.

13. Salvaggio AN, Streich M, Hopper JE, Pierce CA. Why do fools fall in love (at work)? Factors associated with the incidence of workplace romance. J Appl Soc Psychol. 2011;41(4):906-937.

14. Meyer JP, Maltin ER. Employee commitment and well-being: a critical review, theoretical framework and research agenda. JVocat Behav. 2010;77(2):323-337.

15. Wasti SA, Can Ö. Affective and normative commitment to organization, supervisor, and coworkers: do collectivist values matter? JVocat Behav. 2008;73(3):404-413.

16. Casimir G, Lee K, Loon M. Knowledge sharing: influences of trust, commitment and cost. J Knowl Manag. 2012;16(5):740-753.

17. Van Steenbergen EF, Ellemers N. Feeling committed to work: how specific forms of work-commitment predict work behavior and performance over time. Hum Perform. 2009;22(5):410-431.

18. Hatfield E, Rapson RL, Martel LD. Passionate love and secxual desire. In: In Kitayama S, Cohen D, editors. Handbook of Cultural Psychology. New York: Guilford Press; 2007:760-779.

19. Dion KK, Dion KL. Cultural perspectives on romantic love. Pers Relatsh. 1996;3(1):5-17.

20. Yang KS. Chinese personality and its change. In: Bond $\mathrm{MH}$, editor. The Psychology of the Chinese People. Hong Kong: Oxford University Press; 1986:106-170.

21. Burke RJ, Cooper CL. Psychologically intimate, romantic, and sexually intimate relationship in the workplace. In: Burke RJ, Cooper CL, editors. Risky Business: Psychological, Physical and Financial Costs of High Risk Behavior in Organizations. Farnham: Gower; 2010:205-238.

22. Williams CL, Giuffre PA, Dellinger K. Sexuality in the workplace: organizational control, sexual harassment, and the pursuit of pleasure. Annu Rev Sociol. 1999;25(1):73-93.

23. Pierce CA, Aguinis H. Romantic relationships in organizations: a test of a model of formation and impact factors. Manage Res. 2003;1(2):161-169.

24. Mano R, Gabriel Y. Workplace romances in cold and hot organizational climates: the experience of Israel and Taiwan. Hum Relat. 2006;59(1):7-35.

25. Diamond LM, Dubé EM. Friendship and attachment among heterosexual and sexual-minority youths: does the gender of your friend matter? J Youth Adolesc. 2002;31(2):155-166.

26. Anderson CJ, Fisher C. Male-female relationships in the workplace: perceived motivations in office romance. Sex Roles. 1991;25(3-4):163-180.

27. Hatfield E, Sprecher S. Measuring passionate love in intimate relationships. J Adolesc. 1986;9(4):383-410.

28. Dillard JP, Broetzmann SM. Romantic relationships at work: perceived changes in job-related behaviors as a function of participant's motive, partner's motive, and gender. J Appl Soc Psychol. 1989;19(2): 93-110.

29. Debrot A, Schoebi D, Perrez M, Horn AB. Touch as an interpersonal emotion regulation process in couples' daily lives: the mediating role of psychological intimacy. Pers Soc Psychol Bull. 2013;39(10):1373-1385.

30. Koole SL, Tjew A Sin M, Schneider IK. Embodied terror management: interpersonal touch alleviates existential concerns among individuals with low self-esteem. Psychol Sci. 2014;25(1):30-37. 
31. Kark R. Workplace intimacy in leader-follower relationships. In: Cameron K, Spreitzer G, editors. Oxford Handbook of Positive Organizational Scholarship. Oxford: Oxford University Press; 2011: 423-438.

32. Zhang $X$, Long $C$, Wang $Y$, Tang G. The impact of employees' relationships on tacit knowledge sharing. Chin Manag Stud. 2015;9(4):611-625.

33. Sharma J, Dhar RL. Factors influencing job performance of nursing staff: mediating role of affective commitment. Pers Rev. 2016;45(1):161-182.

34. Schoemmel K, Jønsson TS. Multiple affective commitments: quitting intentions and job performance. Empl Relat. 2014;36(5):516-534.

35. Jankowiak WR, Fischer EF. A cross-cultural perspective on romantic love. Ethnology. 1992;31(2):149-155.

36. Hofstede G. Culture and organizations. Int Stud Manag Organ. 1980;10(4):15-41.

37. Dion KK, Dion KL. Psychological individualism and romantic love. J Soc Behav Pers. 1991;6(1):17-33.

38. Dion KK, Dion KL. Individualistic and collectivistic perspectives on gender and the cultural context of love and intimacy. J Soc Issues. 1993;49(3):53-69.

39. Dion KL, Dion KK. Culture and relationships: the downside of selfcontained individualism. In: Sorrentino RM, Cohen D, Olson JM, Zanna MP, editors. Culture and Social Behavior: the Ontario Symposium. Mahwah, NJ: Lawrence Erlbaum Associates; 2005.

40. Kephart WM. Some correlates of romantic love. J Marriage Fam. 1967;29(3):470-474.

41. Goode WJ. The theoretical importance of love. Am Sociol Rev. 1959;24(1):38-47.

42. Rosenblatt PC. Marital residence and the functions of romantic love. Ethnology. 1967;6(4):471-480.
43. Simmons CH, vom Kolke A, Shimizu H. Attitudes toward romantic love among American, German, and Japanese students. J Soc Psychol. 1986;126(3):327-336.

44. Yasmin S. Impact of Higher Education in Understanding of Social Recognition in Women [Ph D thesis]. Islamabad: Pakistan Research Repository, HEC, web site; 2005.

45. Hyder A, Behrman JR. International trade openness and gender gaps in Pakistani labor force participation rates over 57 years. J Asia Pac Econ. 2012;17(3):367-382.

46. Siddiqui R. Modeling gender effects of Pakistan's trade liberalization. Femin Econ. 2009;15(3):287-321.

47. Chan AW, Tong-qing F, Redman T, Snape E. Evaluating the multidimensional view of employee commitment: a comparative UK-Chinese study. Int J Hum Res Manag. 2006;17(11):1873-1887.

48. Baird LS. Self and superior ratings of performance: as related to self-esteem and satisfaction with supervision. Acad Manag J. 1977;20(2):291-300.

49. Hu Lt, Bentler PM. Cutoff criteria for fit indexes in covariance structure analysis: conventional criteria versus new alternatives. Struct Equ Model. 1999;6(1):1-55.

50. Rusbult CE, Martz JM, Agnew CR. The investment model scale: measuring commitment level, satisfaction level, quality of alternatives, and investment size. Pers Relatsh. 1998;5(4):357-387.

51. Becker TE. Potential problems in the statistical control of variables in organizational research: a qualitative analysis with recommendations. Organ Res Methods. 2005;8(3):274-289.

52. Dillard JP, Hale JL, Segrin C. Close relationships in task environments: perceptions of relational types, illicitness, and power. Manag Commun Q. 1994;7(3):227-255.
Psychology Research and Behavior Management

\section{Publish your work in this journal}

Psychology Research and Behavior Management is an international, peerreviewed, open access journal focusing on the science of psychology and its application in behavior management to develop improved outcomes in the clinical, educational, sports and business arenas. Specific topics covered in the journal include: Neuroscience, memory and decision making; Behavior

\section{Dovepress}

modification and management; Clinical applications; Business and sports performance management; Social and developmental studies; Animal studies. The manuscript management system is completely online and includes a very quick and fair peer-review system, which is all easy to use. Visit http://www dovepress.com/testimonials.php to read real quotes from published authors. 